\title{
Can waste foundry sand fully replace structural concrete sand?
}

\author{
Maria Mavroulidou' ${ }^{1}$ David Lawrence ${ }^{1,2}$
}

Received: 16 July 2018 / Accepted: 11 December 2018 / Published online: 19 December 2018

(c) The Author(s) 2018

\begin{abstract}
Foundry sand (FS) waste creates a serious solid waste management problem worldwide due to the high volumes produced, necessitating alternatives to landfilling. A possible route is its use in concrete; however, the current consensus is that FS can only be used for modest sand replacements, based mostly on evidence on concrete with clay-bound FS (greensand). Conversely, this study assessed salient properties of structural concrete with chemically bound FS (polymeric resin binder), for which there is very little information. Concrete mixes were prepared in which FS replaced regular concrete sand partially or fully. The results showed that unlike greensand, the tested chemically bound FS could replace regular concrete sand fully, giving highly workable mixes with good mechanical properties (compressive, splitting and flexural strengths and static modulus of elasticity) similar to those of mixes with regular concrete sand; the effect of FS content on these properties was not statistically significant. Durability in terms of water absorption, carbonation and alkali-silica reaction tests was not adversely affected. The possibility of using high contents of this type of FS in concrete (as opposed to greensand) gives promise for an additional outlet route for large quantities of this waste material with clear economic and environmental benefits.
\end{abstract}

Keywords Industrial solid waste management · Chemically bound foundry sand · Resin-bound foundry sand · Concrete properties $\cdot$ Concrete durability

\section{Introduction}

Foundry sand (FS) waste originates from clean, very uniformly sized and rich in silica, high-quality sand, used by metal foundries for metal casting and moulding processes. It can be repeatedly recycled, crushed down to a raw, uniform sand material and used again for casting, until it degrades and becomes unsuitable for further recycling within the foundry. It is then discarded, creating a serious solid waste management problem due to the large amounts of FS produced worldwide: about one tonne of FS is required for each tonne of iron or steel casting produced. Recent surveys report 6-10 million tonnes of waste FS arising in the USA of which only $15 \%$ is recycled while the remaining waste is landfilled [1, 2]; in Brazil, approximately 3 million tons of waste FS were generated in 2012 [3]; in India approximately

Maria Mavroulidou

mavroum@1sbu.ac.uk

1 London South Bank University, 103 Borough Road, London SE1 0AA, UK

2 WSP Global, WSP House, 70 Chancery Lane, London WC2A 1AF, UK
5000 foundries were reported to produce ca. 1,710,000 tons of waste FS per year [4]; many of these foundries dump the waste causing environmental degradation [5]. In the UK, there are over 450 foundries producing iron, copper and aluminium castings; they generate over 1,000,000 waste FS tonnes per year [6] with the majority arising in the Midlands, South and East Yorkshire. The cost to the UK foundry industry to purchase new sand and subsequently dispose it to landfills is considerable (especially after the introduction of UK landfill tax: $£ 84.40 / t$ and $£ 2.65 / t$ for active and non-active waste respectively), which affects turnover. Consequently, waste FS is typically stockpiled outside the foundries where space for waste storage is limited; waste FS may exceed the volume of on site storage facilities creating an obstacle to production. Moreover, environmental concerns about FS stockpiling were raised in case of contaminant leaching. Therefore foundries have a pressing need to find alternative outlets for waste FS.

Waste FS has been used in geotechnical and highway applications with caution, fearing hazardous substance leaching; although some studies found leachability levels below enforced water quality standards $[7,8]$, recent toxicity studies found FS leachate to interfere with some of the 
studied species although not affecting others [3]. Alternatively, FS can be used in concrete, a very low permeability material, immobilising constituent components, thus minimising contaminant leaching issues. It is produced worldwide in quantities that would greatly outweigh the need of FS disposal. Using waste aggregate in concrete saves nonrenewable mineral aggregate resources whose mining or extraction for concrete manufacturing accounts for approximately $1 \%$ of the total annual $\mathrm{CO}_{2}$ emissions (estimated as 4.1-10.8 million tons annually for the fine aggregate portion in concrete [9]) and entails other serious environmental impacts (e.g. over-extraction of river sand can have major impact on rivers, deltas and ecosystems). Increased environmental awareness thus calls for restrictions in the extraction of river sand with a consequent increase in sand prices [4]. However, for FS to be used in concrete the effects of its grading, surface properties and binder residues need to be assessed as they could make it unsuitable for concrete [8]. These properties are likely to be affected by its industrial use, the casting process, the binders used and the primary metals cast, i.e. ferrous (iron and steel) or non-ferrous metals (aluminium, copper, brass and bronze). Binders can be clay with some carbonaceous additives (producing the so-called 'greensand') or chemical binders (e.g. phenolic urethanes, sodium silicates, epoxy resins, furfuryl alcohol). Unlike greensands, chemically bound sands are free from clay and carbon and coarser in texture. As discussed below, greensands are those that have been extensively researched for their use in concrete, unlike chemically bound FS; the current consensus recommending only modest sand replacements by FS in concrete is thus based mostly on greensand studies. This paper questions this consensus; as it will be shown in the following sections, a number of aspects leading to this recommendation may not apply for chemically bound FS, which were less researched.

\section{Review of the literature}

There is now an abundant literature on greensand concrete plus a number of papers that do not report the type of FS used despite the clear effect that this can have on the resulting concrete properties; however, based on the composition and colour mentioned it can be inferred that most of them used greensand. A variety of cements were used in these works, some including waste or industrial by-products (e.g. [2, 9-11]) and some researchers also replaced coarse aggregates by other waste materials (e.g. $[2,12,13])$. This complicates the interpretation of the results as to the effect of FS itself.

For greensand, due to the presence of clay and hence the increased specific surface of the aggregate, all researchers find a reduction in the concrete workability unless superplasticisers are used or water content adjusted (e.g. [9, $11,14,15]$ - it is believed that the former paper presents greensand although not explicitly stated as introduction only mentions greensand and its typical composition). Concerning mechanical properties of hardened greensand concrete most researchers found reduced compressive strengths, especially for FS contents above $30-40 \%$; for very low FS contents some researchers found an initial increase in the strength, usually followed by a decrease (e.g. [9, 11, 16, 17]) but others found a continuous decrease in strength even at very low FS contents (e.g. [1, 15]). For this reason, few researchers proceeded to full replacement of the regular sand by greensand.

When investigated, tensile strength of greensand concrete showed generally consistent trends with the compressive strength; this is mostly based on splitting cylinder testing (e.g. $[2,9,11,15,18-20])$ with only fewer papers reporting results of flexural strength for greensand ([2,11, 17, 21]). Elastic moduli/stiffness were often simply predicted from the compressive strength using established correlations for regular concrete and not measured $([15,19,20])$; when indicators of stiffness are measured the trends are usually consistent with compressive strength $([2,6,11,14,17])$ with some slight exceptions (e.g. trends in $[12,18])$.

Finally, some papers assessed durability characteristics of greensand FS showing that (a) greensand may lead to higher shrinkage than regular concrete sand (e.g. [15, 21] and [22] for precast concrete blocks with FS—but no such effect was seen in FS bricks); (b) the freeze-thaw resistance of low-strength precast concrete units containing greensand was reduced [22]; (c) conversely greensand increased the chloride penetration resistance of concrete for the tested FS contents - up to $20 \%$ FS [9, 11, 23]; (d) tested FS contents of up to $20 \%$ greensand had good resistance to carbonation [23] and an improved de-icing salt resistance [9]. The water absorption results were inconclusive, as some authors reported a decrease in water absorption with increasing greensand content [19], others a variable effect [16, 23] and others an increase $([15,21]$ and $[6]$-with unknown FS type).

Unlike the now abundant evidence for greensand concrete, only three publications were found explicitly reporting the use of chemically bound FS, namely Etxeberria et al. [12] (chemical binder type not mentioned), Mastella et al. [3] (phenolic resin-bound FS) and Manoharan et al. [24] $\left(\mathrm{Na}_{2} \mathrm{SiO}_{3}\right.$-bound $\mathrm{FS}$, a binder system not recommended for Portland cement [25], initially also containing clay but subsequently washed by the researchers). Of these, Mastella et al. [3] focus on the environmental impact and report only compressive strength results. These papers found generally different or inconclusive results compared to greensand concrete, namely (a) an increase in the slump in [12] as opposed to a decrease in [24] (FS contents of 5-25\%); (b) 

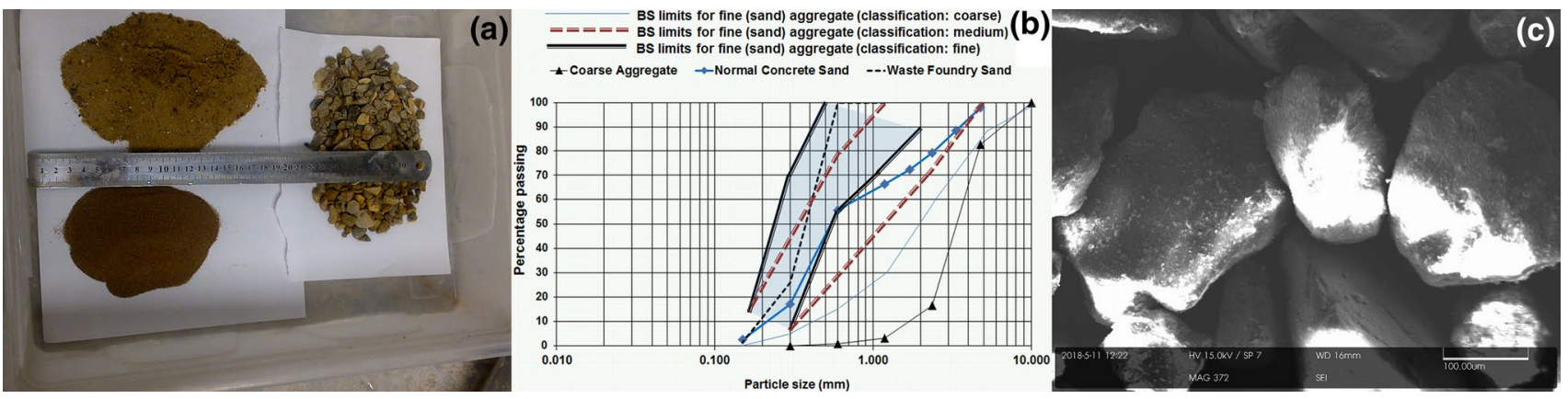

Fig. 1 Particle size and morphology of aggregates. a Photograph of aggregates; b particle size distributions (PSD) against BS limits; $\mathbf{c}$ morphology of FS particles (from SEM)

an increase [12] or otherwise a not statistically significant change in the compressive strength [3] (the latter paper uses FS contents of up to 50\%), and static modulus of elasticity $\mathrm{E}_{\mathrm{c}}$ not exactly consistent with the respective compressive strength results [12]; conversely, Manoharan et al. [24] found little change in the compressive strength or static modulus of elasticity $\mathrm{E}_{\mathrm{c}}$ compared to the control mix for up to $20 \%$ FS but a subsequent small decrease at $25 \%$ FS content (the highest FS content tested); however, splitting tensile strength increased at $25 \% \mathrm{FS}$ content unlike the flexural and compressive strengths; (d) a decrease in the water absorption and hence improved performance [12] or first a small decrease in absorption (5-10\% FS) followed by a slight increase (15-25\% FS) compared to the control mix [24]; (e) no effect on the rapid chloride permeability of the concrete with FS up to $20 \%$ or the abrasion resistance [24].

The performance of chemically bound FS concrete thus appears to differ to that containing greensand. However, the related experimental evidence is insufficient for its use in industrial-scale structural concrete production; the different industrial processes, type and chemical composition (e.g. organic content), the amount of chemical binders and the physical characteristics of the waste FS (differing from those of the greensand) may have varied effects on the resulting concrete properties and these need further investigation.

This paper addresses this particular gap in the knowledge, providing experimental evidence on a wide range of mechanical and durability properties of structural concrete containing alkaline phenolic resin-bound FS (information on durability is scarce or inconclusive even for greensand concrete). Such studies are essential to give confidence in the wider use of this material in industrial-scale structural concrete production, with clear environmental and economical benefits for both foundries and construction industries. Unlike the vast majority of previous studies, the present research proceeds up to full replacements of regular concrete sand by FS. The observations are further supported by mineralogical, microstructural and statistical analysis (the latter is rarely performed in the current literature).

\section{Materials and methods}

\section{Material characterisation}

The aggregates used were (a) Thames river aggregate for the coarse and fine (regular concrete sand) aggregates; (b) "air set" FS for ferrous metal casting from a relatively small foundry in Kent, UK. The "air set" method uses dry sand bonded with a fast-curing chemical adhesive (Alphaset binder), without any clay. Alphaset binders require the addition of an ester component to enable polymerisation of the system to take place. Highly alkaline phenolic resins generally contain suitable alkaline materials to condense these phenolic resins; these usually are potassium or sodium hydroxide (the former being most preferred) but part of the alkali metal hydroxide may be substituted by a divalent metal hydroxide, e.g. calcium or magnesium hydroxide [26].

The waste FS as provided by the factory (ready for disposal) is already screened and crushed and free of lumps or dust (see Fig. 1a); there are no impurities such as clay or ash unlike all other FS photos shown in the literature (e.g. [2, 20]). Namely, for reclamation and reuse within the foundry a mechanical reclamation process is used: after primary attrition (shakeout, vibration, screening), the sand undergoes secondary attrition in a 'USR' Secondary Attrition Unit (Omega Foundry Machinery Ltd.) for further binder removal. The main components of this unit are the secondary attrition cell consisting of (a) a ceramic lined rotating drum-centrifugal attrition, (b) ceramic rollers squeezing and forcing the sand grains together for greater attrition and binder removal, and (c) activating cylinders and drive motor, the fluidised bed, the dust separation chamber and the control panel. This is particularly suitable for the alkaline phenolic binder process: it removes a significant portion of the binder without thermal processing, allowing for up to $90 \%$ improvement in the mechanical reclamation of FS [27]. According to personal communication from the foundry, this process allows for approximately $80 \%$ of the sand to be reused in the foundry (typically 3-4 times) but still $20 \%$ of 
Table 1 Physicochemical properties of the two sands

\begin{tabular}{lll}
\hline & Regular concrete sand & Waste FS \\
\hline Particle shape $^{\mathrm{a}}$ & Subangular & $\begin{array}{c}\text { Rounded or } \\
\text { sub- } \\
\text { rounded }\end{array}$ \\
& & 1.7 \\
Fineness modulus & 2.8 & 2.59 \\
Particle density (oven dried) $-\mathrm{Mg} / \mathrm{m}^{3 \mathrm{~b}}$ & 2.56 & 2.61 \\
Particle density (sat. surf. dried) $-\mathrm{Mg} / \mathrm{m}^{3 \mathrm{~b}}$ & 2.59 & 2.64 \\
Particle density (apparent)- $\mathrm{Mg} / \mathrm{m}^{3 \mathrm{~b}}$ & 2.63 & 0.63 \\
Water absorption (\%) & 1.05 & 8.5 \\
pH & 8.1 & 0.9 \\
Loss of ignition (\%) (LOI) & 1.0 & \\
\hline
\end{tabular}

${ }^{\text {a } D e t e r m i n e d ~ b y ~ v i s u a l ~ i n s p e c t i o n ~ u s i n g ~ a n ~ a n a l o g u e ~ m i c r o s c o p e ~ a n d ~ S E M ~(s e e ~ F i g . ~ 1 c) ~}$

${ }^{b}$ Determined based on BS 812-2: 1995 [29] sand remains for landfilling, as it is unsuitable for further use in the foundry.

Physicochemical properties of the FS compared to regular concrete sand are shown in Table 1; photos of all aggregates and corresponding particle size distribution (PSD) are shown in Fig. 1a, b. According to its PSD waste FS was very uniform as opposed to the well-graded regular concrete sand (controlling the uniformity of the sand system is one of the most critical parts of the foundry casting process) and overall finer compared to the regular concrete sand (all particles pass the $600-\mu \mathrm{m}$ sieve and less than $5 \%$ pass the $150-\mu \mathrm{m}$ sieve) (Fig. 1b). However, the FS PSD curve still falls within the British Standards (BS) limits for fine concrete aggregate [28] and could thus be acceptable for up to $100 \%$ fine aggregate replacement. Despite its finer size, the FS aggregate had a lower water absorption than regular concrete sand (see Table 1), presumably due to water-repelling binder remains. Conversely, greensand has higher water absorption than regular concrete sand, due to clay and ash binders [20]. Our FS had no fraction in the fine-grained soil size $(0.063 \mathrm{~mm}$ according to BS) unlike typical FS reported in the literature that contains $5-12 \%$ of fines [4]. This confirms that the vast majority of previously published papers deal with a different type of sand (likely to be greensand, if not mentioned explicitly). Despite the slightly darker colour implying possible binder remains, XRD analysis of the as received waste FS showed clearly only one phase, i.e. all significant peaks were assigned to quartz (ICDD reference code 00-046-1045), i.e. $\mathrm{SiO}_{2}$ (see Fig. 2). Thus, any binder remains are too small to be detectable at this level. The phase purity/lack of other phases is consistent with our visual observation that there were no impurities in the FS used in this study.

To assess further the morphology of the FS particles and its chemical composition, a Jeol JSM-6400scanning electron microscope (SEM) configured with Oxford Instruments INCA X-sight energy-dispersed spectrum (EDS) analyser was used. Two different spectra from a number of sites on different FS particles were analysed; the first spectrum (s1) corresponds to background locations representative of the largest part of the respective particle (according to the corresponding SEM photo), whereas spectrum 2 (s2) is located where some different features can be seen in the SEM, potentially linked to binder remains. Indicative SEM photos with related EDS analysis spectra are shown in Fig. 3. These consistently showed the main element in all sites to be $\mathrm{Si}$ as expected with significant $\mathrm{O}_{2}$ peaks as well, which is consistent with the XRD analysis (highsilica-content sand). In site 1 (Fig. 3a), there is a higher $\mathrm{C}$ content (i.e. higher peaks) in spectrum 2 (s2) compared to spectrum 1 (s1) and lower Si content, which could be attributed to organic binder remains (there is always some $\mathrm{C}$ in the sample due to carbon coating for SEM testing but the much higher $\mathrm{C}$ content in $\mathrm{s} 2$ indicates a potential different source of $\mathrm{C}$ ); there are also higher $\mathrm{K}$, as well as $\mathrm{Ca}$ and $\mathrm{Na}$ peaks in $\mathrm{s} 2$ also indicators of potential binder remains according to the typical composition of the alkaline phenolic binder system (see above). Very little Fe can be seen and it is not very different in the two spectra. In site 2 (Fig. 3b), spectrum 1 (s1) is overall similar to $\mathrm{s} 1$ of site1; spectrum 2 (s2) shows again $\mathrm{K}$ peak consistent with the $\mathrm{KOH}$ used in the binder and higher $\mathrm{Ca}$ than in site1. There is also a small Al peak (as in site1) but very little $\mathrm{Na}$ or Fe. In site 3 (Fig. 3c), spectrum 1 (s1) contains as always $\mathrm{Si}$ and $\mathrm{O}$ and also $\mathrm{Ca}, \mathrm{Na}$, and some $\mathrm{K}$ whereas $\mathrm{Al}$ and $\mathrm{Fe}$ peaks are very similar to those in all other sites; there are again higher $\mathrm{Ca}$ as well as $\mathrm{K}$ and $\mathrm{O}$ peaks in $\mathrm{s} 2$ consistent with the alkaline binder composition, and some $\mathrm{Al}$ and very small Fe peaks similar to the other sites' s2 spectra. Note that Au found everywhere is due to gold coating in SEM sample preparation. 


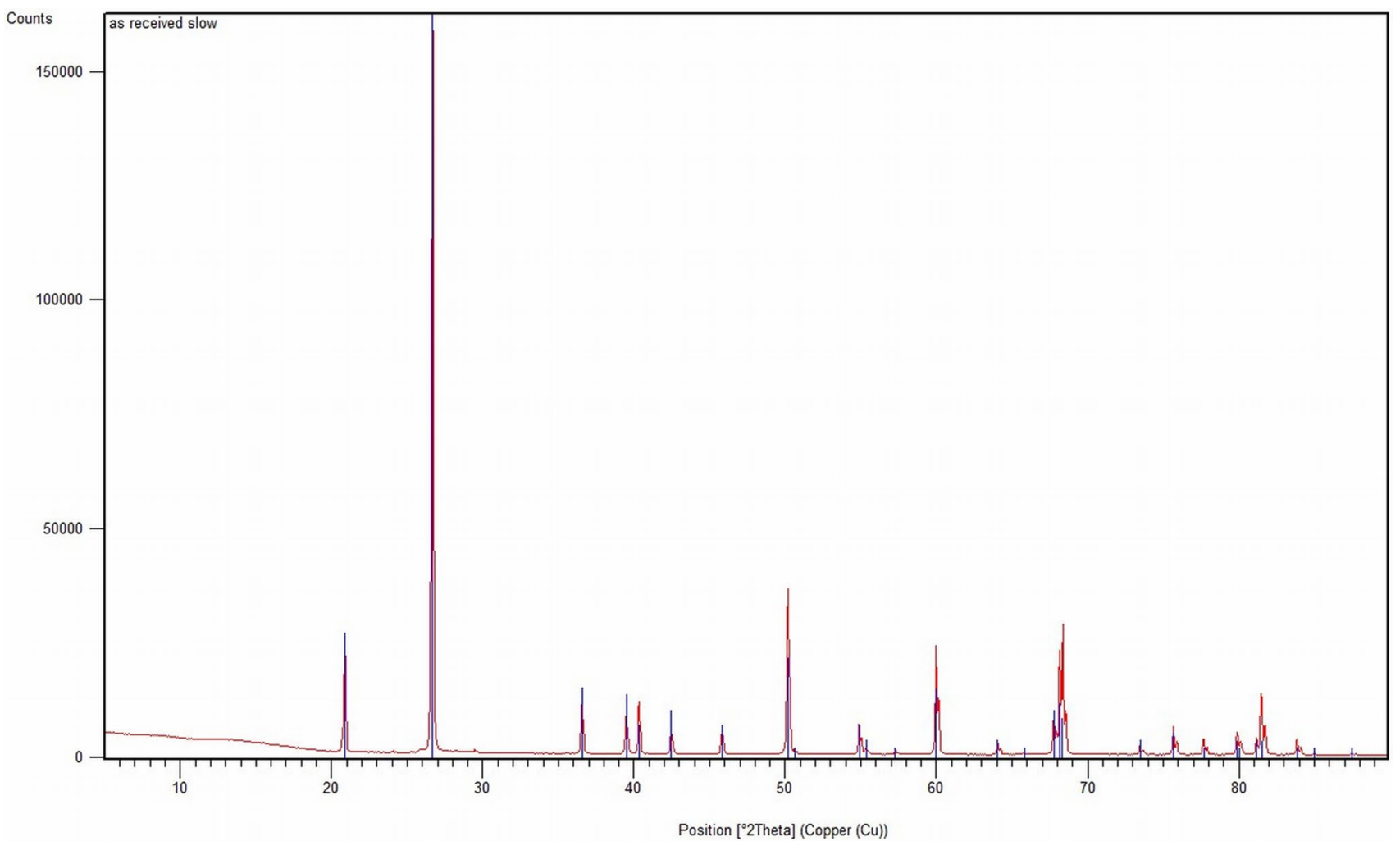

Fig. 2 Mineralogical composition of FS

\section{Mix design and casting}

Concrete was created with a mix design of 1:1.5:3 (1 part Limestone Portland Cement CEM-II/A-L 32; 1.5 parts sand and 3 parts coarse aggregate) according to BS 5328 [30] using a rotating mixer. Control mixes containing only regular concrete sand were first made; subsequently, waste FS replaced regular sand at increasing percentages per total sand mass, until full replacement (Table 2). For consistent comparisons, the water/cement ratio $(w / c)$ was kept constant for each set of mixes (i.e. $w / c=0.55$ or 0.45 , respectively). Specimens were cast in moulds in three separate layers compacted on a vibrating table for approximately $15 \mathrm{~s}$, to remove entrapped air. Good concrete mixes were obtained for all FS contents as the apparent densities of the regular sand and FS were very similar (see Table 1) preventing segregation, often observed when using waste material aggregates of different nature (e.g. metal slags or tyre crumbs).

Table 2 also reports the workability based on slump measured immediately after mixing [31] and the air content of fresh mixes assessed using the water column method [32]. All FS mixes with $w / c$ of 0.55 had very high slumps, equal or slightly higher than the control mix; $0.45 \mathrm{w} / \mathrm{c}$ mixes had more variable slumps but still equal or higher than the control mix slump (namely high $(80-155 \mathrm{~mm}$ ) or very high (160 mm and above) slumps). It is thus clear that the workability of the concrete mixes was not adversely affected, consistently with Etxeberria et al. [12] for chemically bound FS; instead, during mix preparation we noted that generally the higher the FS, the more workable the concrete mix became. The opposite was found for greensand. Angularity and smaller size (higher specific surface) usually reduce workability [33]; our FS is rounded, so the two effects are antagonistic. More importantly, the reduced particle water absorption (Table 1) leaves more free water in the mix ensuring workability. The air content of FS mixes initially decreased, then gradually increased but remained lower than that of the control mix for all FS contents, indicating an improved performance of FS mixes (entrapped air causes voids to form, reducing strengths and durability) presumably because rounded FS grains compact better.

\section{Curing and testing procedures}

After casting, fresh concrete specimens were covered with a plastic sheet for $24 \mathrm{~h}$; they were then demoulded and water cured at $20{ }^{\circ} \mathrm{C}\left( \pm 2{ }^{\circ} \mathrm{C}\right)$ until required for testing. The following tests were performed: cube compressive strength (100 $\mathrm{mm}$ cubes) [34]; indirect tensile strength testing i.e. (a) the tensile splitting strength of 150-mm-diameter and 300-mm-high cylinders [35] — these cylinders were also used for static modulus of elasticity testing [36]; (b) the two-point 

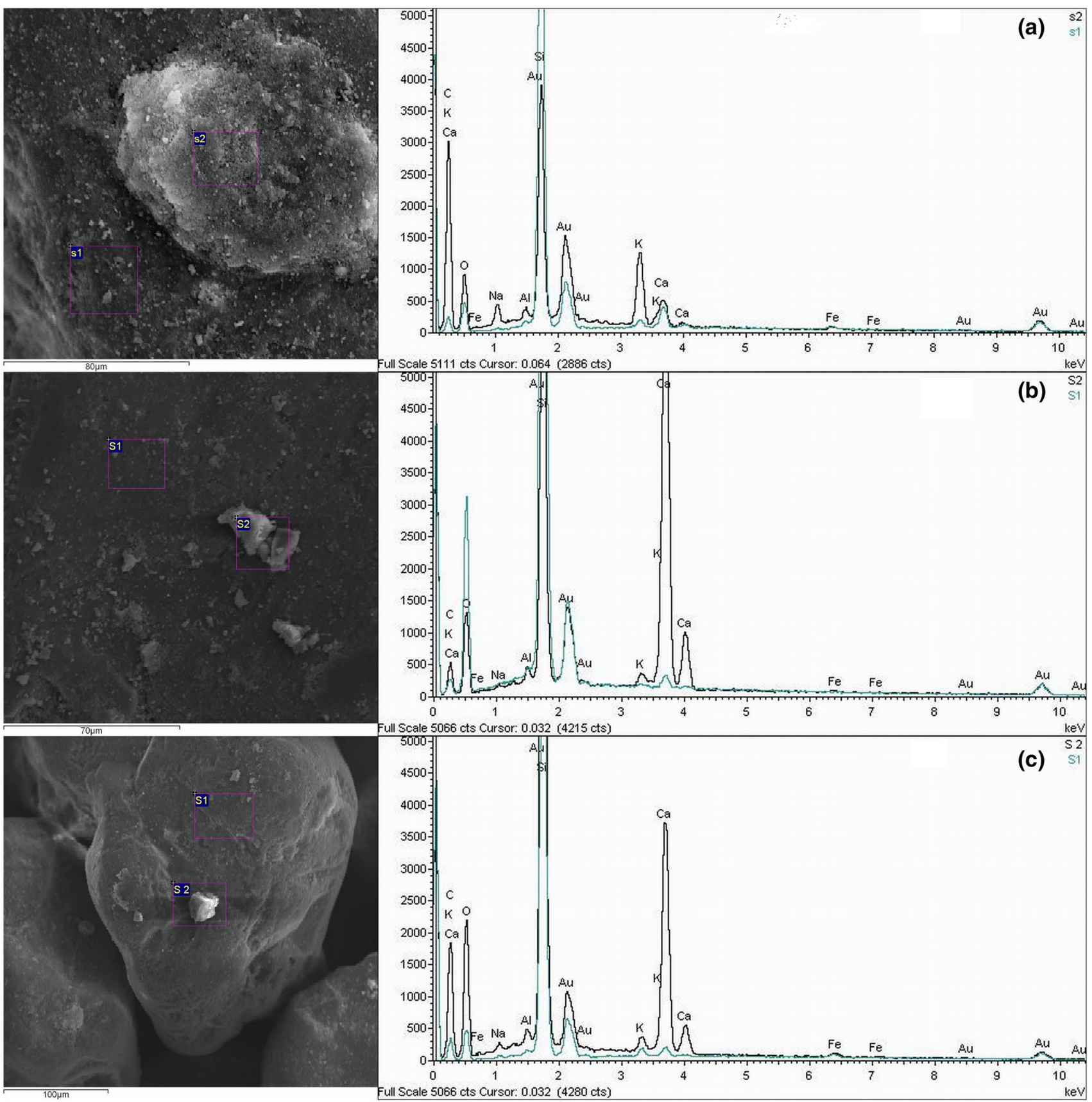

Fig. 3 Chemical composition of FS grains based on EDS analysis on three different FS sample sites

flexural strength of beams of $500 \mathrm{~mm}$ length and a section of $100 \mathrm{~mm} \times 100 \mathrm{~mm}$ [37]. Durability was assessed based on (a) water absorption [38]; (b) accelerated alkali-silica reaction (ASR) testing [39]; (c) carbonation testing [40] on specimens left outdoors for 1.5 year, partly protected by a roof (i.e. conditions favouring carbonation). Six specimens per mix per curing time were tested for the cube compressive strength and carbonation testing, three for water absorption and splitting tensile strength, whereas beams and mortar bars for ASR testing were cast in duplicate.

\section{Results and discussion}

\section{Cube compressive strength}

FS had a variable effect (increase or decrease in strength) but differences in strengths compared to the respective control mixes for 0.55 and $0.45 w / c$ ratios were small for all FS percentages, including full replacement (Fig. 4a, b), unlike results for greensand. Differences could thus be due to the usual concrete batch variability, without any significant 
Table 2 Mix design proportions $\left(\mathrm{kg} / \mathrm{m}^{3}\right)$ and fresh concrete properties

\begin{tabular}{|c|c|c|c|c|c|c|c|}
\hline Mix ID & CEM-II $\left(\mathrm{kg} / \mathrm{m}^{3}\right)$ & $\begin{array}{l}\text { Regular con- } \\
\text { crete sand }(\mathrm{kg} / \\
\left.\mathrm{m}^{3}\right)\end{array}$ & $\begin{array}{l}\text { Waste foundry } \\
\text { sand (FS) }(\mathrm{kg} / \\
\left.\mathrm{m}^{3}\right)\end{array}$ & $\begin{array}{l}\text { Coarse aggregate } \\
(10 \mathrm{~mm})\left(\mathrm{kg} / \mathrm{m}^{3}\right)\end{array}$ & Water $\left(\mathrm{kg} / \mathrm{m}^{3}\right)$ & Slump (mm) & Air content $(\%)$ \\
\hline FS0_w/c_055 & 397 & 595 & 0 & 1190 & 218 & 200 & 2.2 \\
\hline FS10_w/c_055 & 397 & 535.5 & 59.5 & 1190 & 218 & 210 & 1.7 \\
\hline FS30_w/c_055 & 397 & 416.5 & 178.5 & 1190 & 218 & 210 & 1.7 \\
\hline FS50_w/c_055 & 397 & 297.5 & 297.5 & 1190 & 218 & 210 & 1.8 \\
\hline FS70_w/c_055 & 397 & 178.5 & 416.5 & 1190 & 218 & 200 & 1.9 \\
\hline FS100_w/c_055 & 397 & 0 & 595 & 1190 & 218 & 200 & 2 \\
\hline FS0_w/c_045 & 403.5 & 605 & 0 & 1210 & 181.5 & 120 & Not measured \\
\hline FS10_w/c_045 & 403.5 & 544.5 & 60.5 & 1210 & 181.5 & 120 & \\
\hline FS30_w/c_045 & 403.5 & 423.5 & 181.5 & 1210 & 181.5 & 120 & \\
\hline FS50_w/c_045 & 403.5 & 302.5 & 302.5 & 1210 & 181.5 & 120 & \\
\hline FS70_w/c_045 & 403.5 & 181.5 & 423.5 & 1210 & 181.5 & 170 & \\
\hline FS100_w/c_045 & 403.5 & 0 & 605 & 1210 & 181.5 & 160 & \\
\hline
\end{tabular}
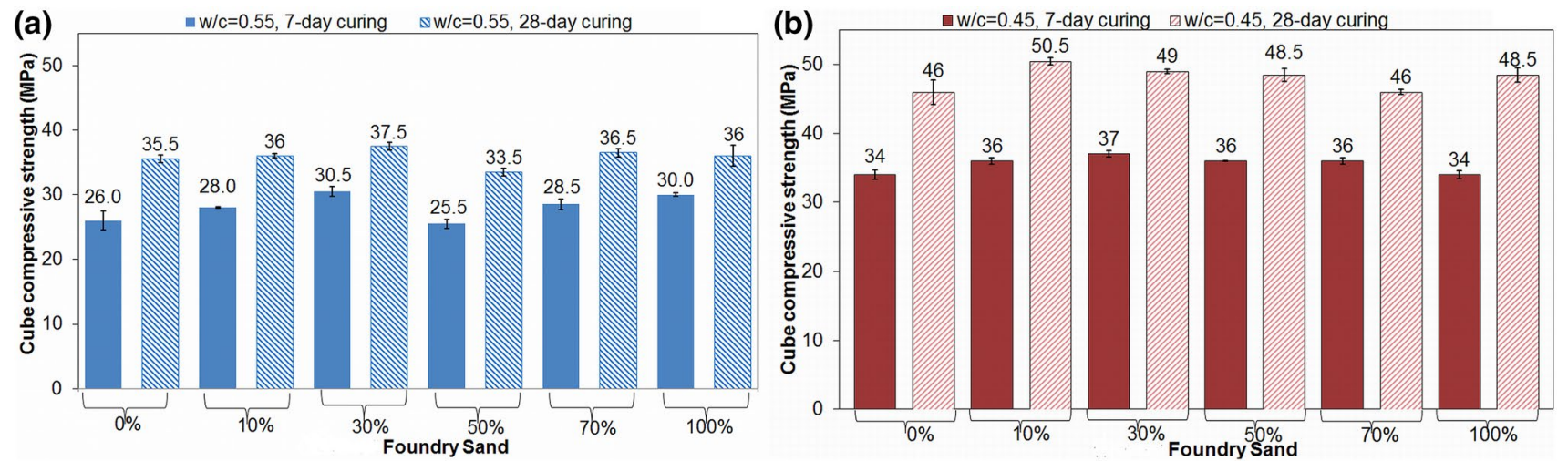

Fig. 4 Compressive strength results. a Mixes with $w / c=0.55$; $\mathbf{b}$ mixes with $w / c=0.45$

trends (this is investigated statistically in "Statistical analysis"). The good strengths can be due to some filler effect of the rounder, uniform and finer FS sand reducing the void ratios [19]. Moreover, all FS concrete mixes were of appropriate consistency, giving good quality concrete of adequate strength. SEM-EDS analysis (Fig. 5a-d) showed similar structure and chemical composition in both FS and control mixes (with FS mixes having somewhat higher Si content presumably due to the Si content of the FS) and the development of C-S-H hydration products (see the uniformly spread reticular network of aggregated crystals), hence the good strength of FS mixes.

\section{Tensile strength}

The 28-day splitting tensile strength and flexural strength, rounded to the closest $0.05 \mathrm{MPa}$ and the closest $0.1 \mathrm{MPa}$, respectively (Fig. 6a, b), are generally consistent with the compressive strength results (confirmed by the very strong correlations in Fig. 6c, d). Splitting strengths were about $6-7 \%$ and flexural strengths about $10 \%$ of the respective compressive strength values, consistently with common empirical rules of thumb for concrete with regular sand. Flexural strength values of most FS mixes were almost constant, with differences of $\pm 2.7 \%$ with respect to the $w / c=0.55$ control mix and with a maximum difference of $6.5 \%$ for the $w / c=0.45 \mathrm{mix}$. As expected, there was a very strong correlation between the two different indirect measures of the tensile strength of concrete (Fig. 6e). Overall for all FS contents, indirect tensile strength values were close (in most cases equal or higher) to that of the respective control mix. Thus, unlike greensand, our chemically bound FS did not affect adversely tensile strength at high FS contents.

\section{Static modulus of elasticity $E_{c}$}

The $E_{\mathrm{c}}$ results (Fig. 7a) also followed generally the compressive strength trends, as in regular sand concrete (see the 
Fig. 5 Indicative SEMEDS results. a SEM-EDS

FS0_w/c_0.45, $50 \mu \mathrm{m} ; \mathbf{b}$ SEMEDS FS100_w/c_0.45, $50 \mu \mathrm{m} ; \mathbf{c}$ SEM FS0_w/c_0.45, $100 \mu \mathrm{m} ; \mathbf{d}$ SEM FS100_w/c_0.45, $100 \mu \mathrm{m}$

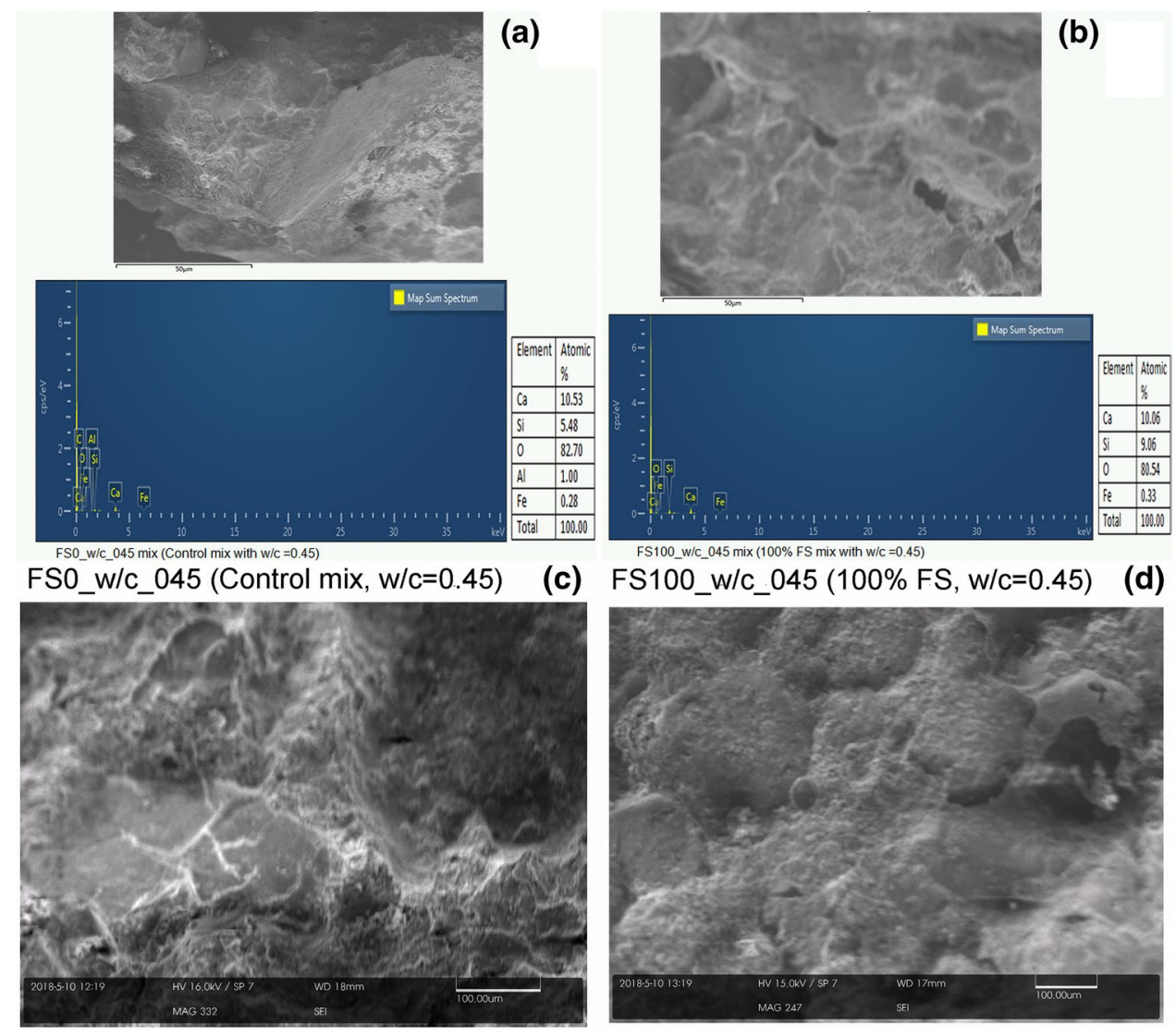

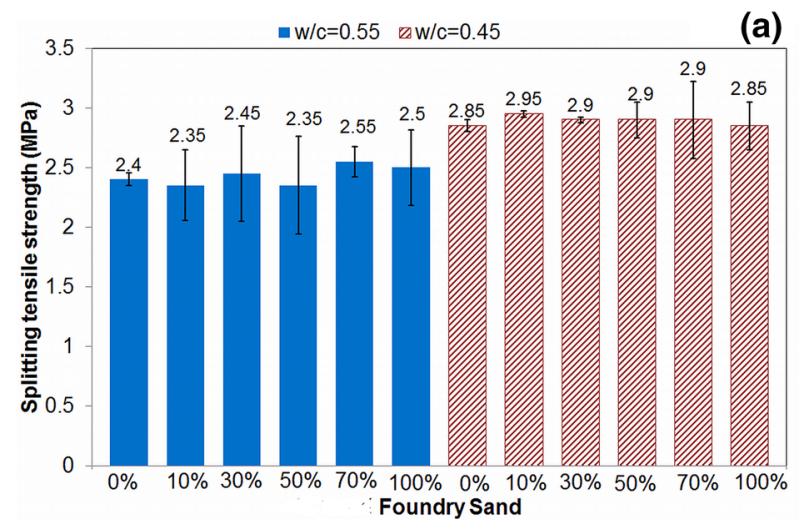

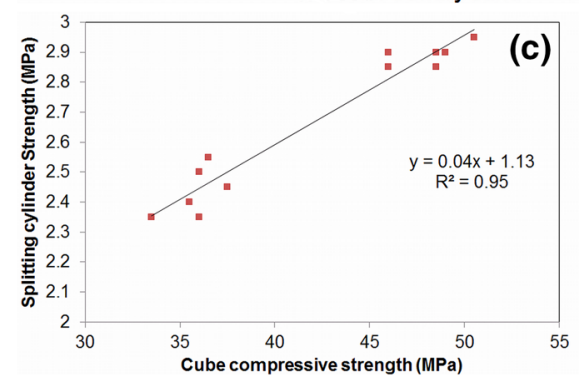

(a)
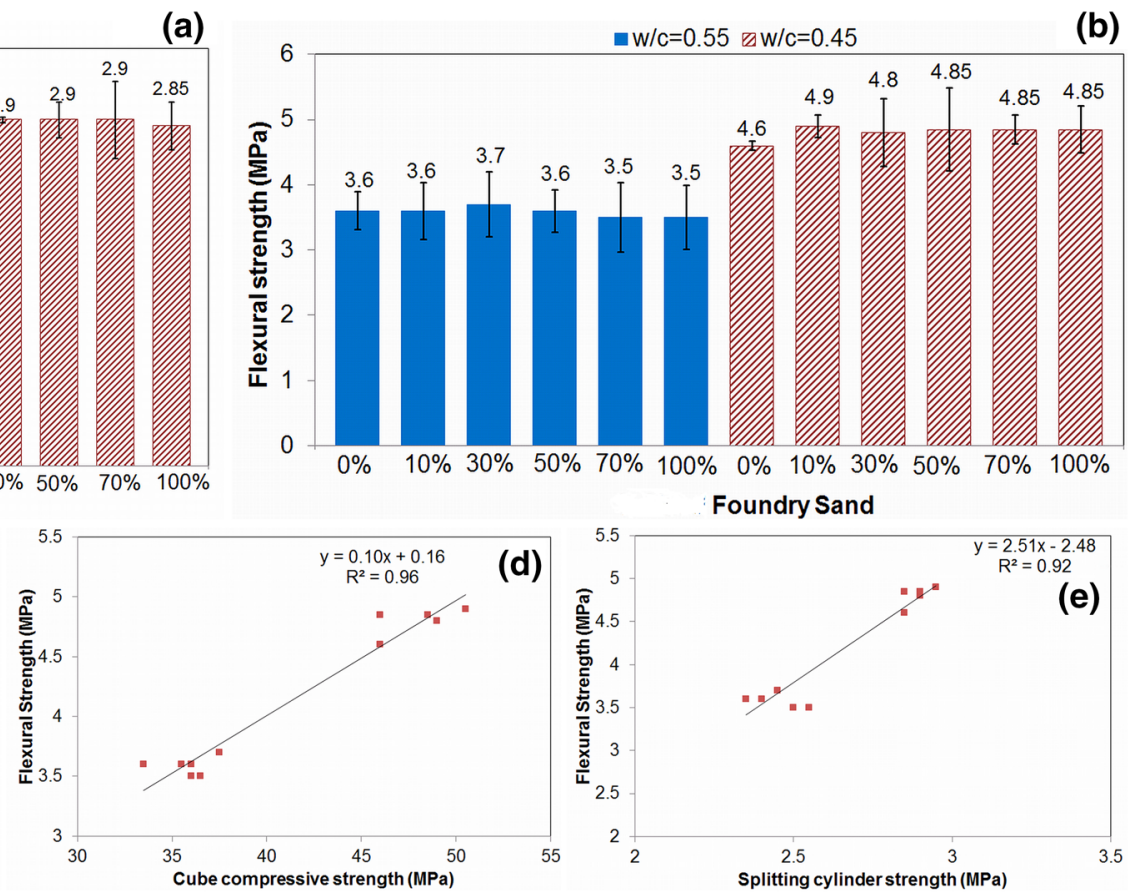

Fig. 6 28-day tensile strength results a splitting cylinder tensile strengths; $\mathbf{b}$ flexural strengths; $\mathbf{c}$ correlation of splitting cylinder and cube compressive strengths; $\mathbf{d}$ correlation of flexural and cube compressive strengths; e correlation of splitting cylinder and flexural strengths 

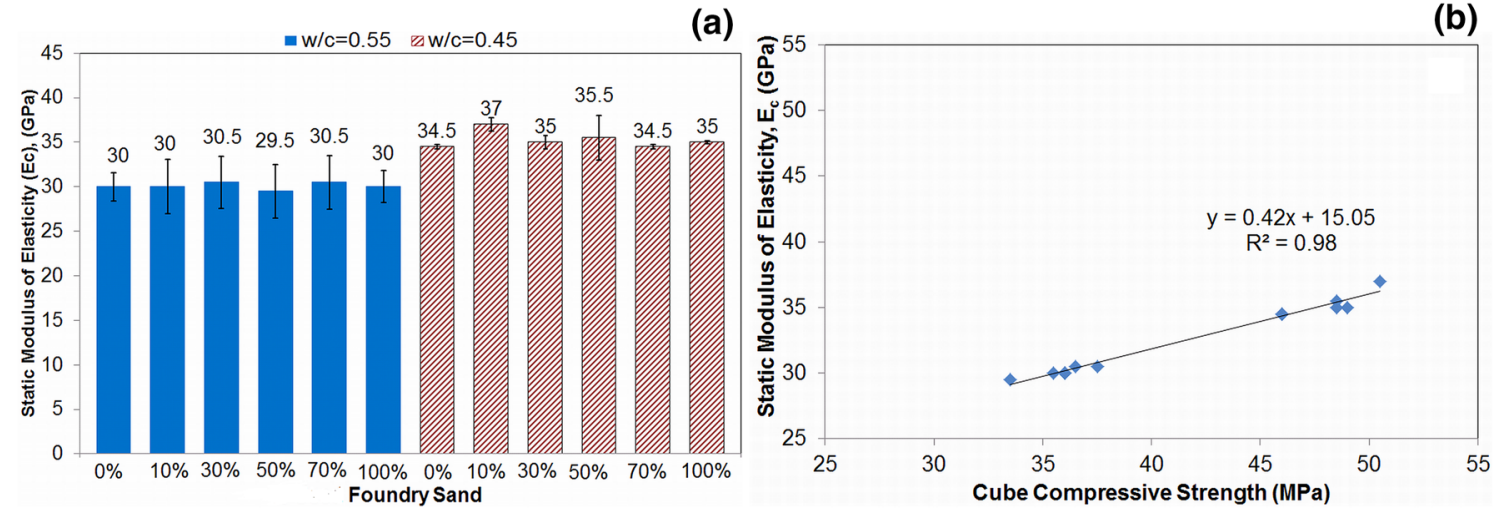

Fig. 7 28-day static modulus of elasticity $\left(E_{\mathrm{c}}\right)$ a testing results; $\mathbf{b}$ correlation of $E_{\mathrm{c}}$ with 28-day cube compressive strengths

Fig. 8 28-day water absorption results

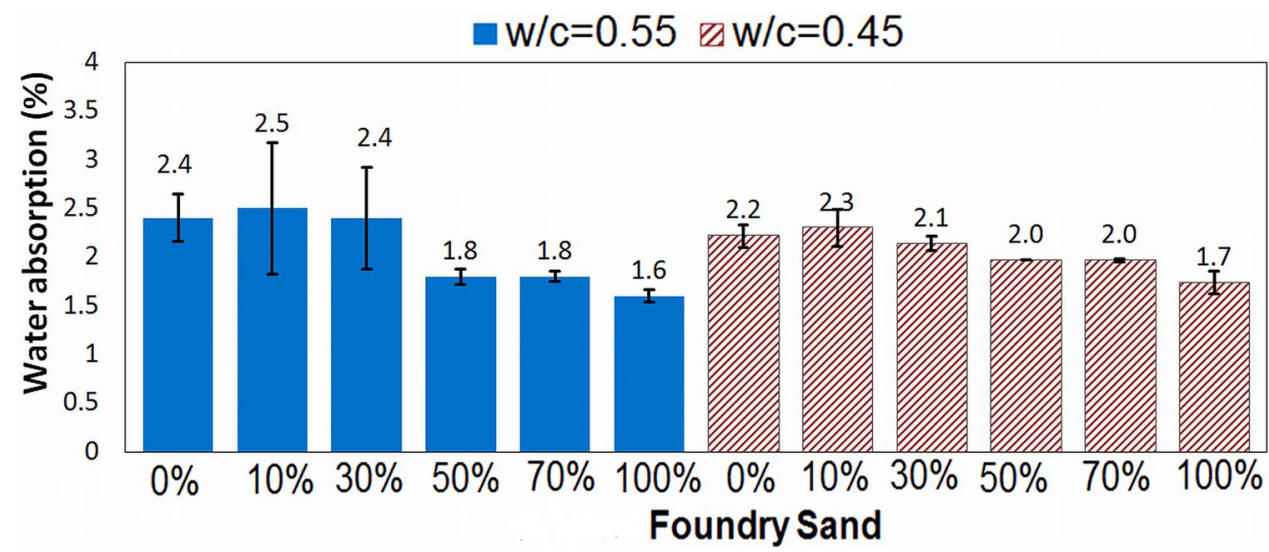

very strong correlation in Fig. 7b). This agrees with some greensand concrete results with modest FS contents [9, 11, 17]; however, Fig. 7a shows no adverse effects on $E_{\mathrm{c}}$ up and to full regular sand replacement.

\section{Durability tests}

\section{Water absorption}

FS mixes had equal or lower absorption levels than the control mix, especially for FS of above $30 \%$ (Fig. 8), consistently with the lower air contents of Table 2 (hence less voids reducing water ingress) and the filler effect of FS. This agrees with Guney et al. [20] (using up to $15 \%$ greensand); others found an initial decrease in the absorption followed by a sharp increase at higher greensand contents [16] or a monotonic increase in absorption with increasing greensand contents [15]. SEM pictures (Fig. 3a-d) do not show any clearly marked differences in the void network structure between FS and control mixes (some microcracks and voids can be seen in both mixes but overall dense interfacial transition zones are apparent).

\section{Carbonation}

The natural carbonation after 1.5 years increased with increasing FS levels for $w / c=0.45$ : observed average carbonation depths (recorded to the nearest $0.5 \mathrm{~mm}$ ) were 2, 3.5 and $4 \mathrm{~mm}$, respectively, for $10 \%, 50 \%$ and $100 \% \mathrm{FS}$; conversely, carbonation depths of $0.55 \mathrm{w} / \mathrm{c}$ specimens decreased with increasing FS levels (5, 4.5 and $2.5 \mathrm{~mm}$ for $10 \%, 50 \%$ and $100 \%$ FS, respectively) possibly due to the reduced air voids (Table 2). The overall performance was, however, similar to regular limestone cement concrete (i.e. carbonation depths of $3.2 \mathrm{~mm}$ and $4.6 \mathrm{~mm}$ for $w / c$ of 0.45 and 0.55 , respectively, for 1 year of natural carbonation [41]).

\section{ASR}

The test was conducted on the control and $100 \%$ FS mixes (100\% FS would constitute a worst-case scenario if the FS aggregate was reactive). Virtually null expansions were observed, all well below the ASTM limit of $0.1 \%$ [37] implying that there were no deleterious reactions between alkalis in cement with the high-silica-content FS. 


\section{Statistical analysis}

To verify whether FS content affected concrete properties significantly we performed statistical analysis (using R software) in the form of $n^{k}$ factorial experiments (with replications) with two factors $(k=2)$ and two levels of the factors $(n=2)$, i.e. FS content (FS) - the two levels assigned were "low" and "high" and w/c (WC) - " 0.45 " and " 0.55 " levels. We analysed mechanical property results (cube compressive strength, splitting cylinder, flexural strength and modulus of elasticity) at 28-day curing (the usual industry-wide reference strength of concrete) and slump (workability is another property observed in concrete mix design). Interaction plots did not reveal any clear interaction effects of the two factors; boxplots, histograms and normal probability quantile-quantile (QQ) plots of the datasets ${ }^{1}$ showed that the normality and/or homogeneity of variance ANOVA assumptions were violated (confirmed by Shapiro-Wilk normality test and Fligner-Killeen test of homogeneity of variances). Therefore, the main effects were assessed using Kruskal-Wallis non-parametric analysis. For all analysed properties, the only statistically significant factor was the $w / c$ (with all $p$ values $<0.004$ ); the FS content (with all $p$ values $>0.6$ ) was not statistically significant. This agrees with Torres et al. [2] showing that the compressive strength increase with greensand—up to $30 \%$ used—was not statistically significant.

\section{Conclusion}

The paper presented a comprehensive parametric study on a wide range of properties and durability characteristics of concrete with chemically bound FS, on which there is little information. The physical properties of the tested FS would be acceptable for use in concrete according to BS; similar (or better) fresh and hardened concrete characteristics and durability to that of regular concrete were observed up to full sand replacements. Therefore, findings for greensand are clearly different and should not be generalised to chemically bound FS concrete; instead, further dedicated research on this material is required to generalise the findings to other types of chemically bound sand considering the wide range of chemical binders used. Additional long-term durability studies of FS concrete would also be required to produce this material for the market with confidence.

The results are, however, encouraging regarding the feasibility of using chemically bound FS in concrete at much higher replacement levels of regular sand compared to greensand (even full replacements) with no apparent adverse effects on the concrete. Our findings were based on FS that

\footnotetext{
${ }^{1}$ Not shown here for brevity.
}

underwent secondary attrition as a standard process within the factory for sand reclamation. This is cheaper to purchase or operate than thermal reclamation; hence, a cost-effective alternative but still giving suitable quality sand for concrete. Pre-processing could be used for other FS types [5] including greensands, if their fine portions and impurities were removed; this could be minimised to save costs (a barrier to recycling in some countries) and still give adequate FS for concrete [2].

The key conclusion from this work is that although caution must be exerted for applications of waste materials in construction, the usually recommended threshold of $30 \%$ FS in concrete may have to be reviewed on a case to case basis, to potentially maximise environmental and economic benefits. The FS is commonly treated anyway for reuse within the factory and the waste FS is the portion of this FS that can no longer be reused; thus, excluding transportation costs, if this waste FS portion was deemed to be suitable for use in concrete (as the presented research indicates) it would not incur additional costs, compared to $£ 50 /$ tonne for natural concrete sand (our suppliers' prices). It would greatly reduce landfilling costs to foundries, in terms of transport, disposal and landfill taxes where applicable (considering that treatment would be a standard practice in the foundry whether FS is landfilled or used in concrete). As an example, the relatively small UK foundry that supplied the FS buy 40 tonnes of sand monthly, of which about $20 \%$ will result in waste FS; disposal incurs costs of up to $£ 2000$ per month to the foundry. The prospect of reusing this waste FS in concrete, with many concrete plants operating in the nearby area (rendering this recycling route feasible), would be very beneficial for the foundry.

FS properties will vary from one foundry to another; for market feasibility, the quality of waste FS from different sources (necessary to meet the demands for concrete aggregate quantities) should be consistent. This is a general issue for any suggested waste materials for concrete, given the high variability and relatively limited volume of waste materials generated from any single process (compared with the usual throughput of a commercial-scale cement or concrete production facility). Eventually, the viability of using FS in concrete will depend on local economics, i.e. cost, availability of the FS in sufficiently large quantities and availability and costs of natural aggregates in the regions where concrete is produced.

Acknowledgements The authors would like to express their deep gratitude to Professor Neil Alford (Imperial College, London), for enabling access to the Imperial College Department of Materials laboratories as well as to Mr. Richard Sweeney and Dr. Mahmoud Ardakani for the mineralogical and SEM-EDS analysis of the foundry sand at Imperial College. The authors would also like to thank Mr. Christopher Gray, Graham Bird, Paul Elsdon, David Metcalfe and Ken Unadkat (LSBU technical staff) for their help with material characterisation and testing. 
OpenAccess This article is distributed under the terms of the Creative Commons Attribution 4.0 International License (http://creativeco mmons.org/licenses/by/4.0/), which permits unrestricted use, distribution, and reproduction in any medium, provided you give appropriate credit to the original author(s) and the source, provide a link to the Creative Commons license, and indicate if changes were made.

\section{References}

1. Monosi S, Tittarelli F, Giosue C, Ruello ML (2013) Effect of two different sources and washing treatment on the properties of UFS by-products for mortar and concrete production. Constr Build Mater 44:260-266

2. Torres A, Bartlett L, Pilgrim C (2017) Effect of foundry waste on the mechanical properties of Portland Cement Concrete. Constr Build Mater 135:674-681

3. Mastella MA, Gislon ES, Pelisser F, Ricken C, Silva L, Angioletto E, Montedo ORK (2014) Mechanical and toxicological evaluation of concrete artifacts containing waste foundry sand. Waste Manag 34(8):1495-1500

4. Bhardwaj B, Kumar P (2017) Waste foundry sand in concrete: a review. Constr Build Mater 156:661-674

5. Gurumoorthy N, Arunachalam K (2016) Micro and mechanical behaviour of treated used foundry sand concrete. Constr Build Mater 123:184-190

6. Khatib JM, Herki BA, Kenai S (2013) Capillarity of concrete incorporating waste foundry sand. Constr Build Mater 47:867-871

7. Naik TR, Singh SS, Ramme WB (2001) Performance and leaching assessment of flowable slurry. J Environ Eng 127(4):359-368

8. FIRST (2004) Foundry sand facts for civil engineers. Report no FHWA-IF-04-004. Federal Highway Administration Environmental Protection Agency, Washington DC

9. Siddique R, Singh G, Singh M (2018) Recycle option for metallurgical by-product (Spent Foundry Sand) in green concrete for sustainable construction. J Clean Prod 172:1111-1120

10. Sathees Kumar M, Prabu M, Suganya S (2017) Influence of foundry sand and hypo sludge in concrete. IJIRSET 6(3):4261-4268

11. Siddique R, Singh G, Belarbi R, Ait-Mokhtar K, Kunal (2015) Comparative investigation on the influence of spent foundry sand as partial replacement of fine aggregates on the properties of two grades of concrete. Constr Build Mater 83:216-222

12. Etxeberria M, Pacheco C, Meneses JM, Berridi I (2010) Properties of concrete using metallurgical industrial by-products as aggregates. Constr Build Mater 24:1594-1600

13. Smarzewski P, Barnat-Hunek D (2016) Mechanical and durability related properties of high performance concrete made with coal cinder and waste foundry sand. Constr Build Mater 121:9-17

14. Monosi S, Sani D, Tittarelli F (2010) Used foundry sand in cement mortars and concrete production. Open Waste Manag J 3:18-25

15. Basar MH, Aksoy ND (2012) The effect of waste foundry sand (WFS) as partial replacement of sand on the mechanical, leaching and micro-structural characteristics of ready-mixed concrete. Constr Build Mater 35:508-515

16. Marchioni ML, Lyra J, Pileggi R, Pereira RL, Oliveira C (2012) Foundry sand for manufacturing paving units. In 10th International conference on concrete block paving Shanghai, November 24-26, 2012. http://www.sept.org/techpapers/Marchioni-onFoundry-Sand-in-Paving-Units.pdf. Accessed 13 July 2018

17. Siddique R, de Schuter G, Noumowe A (2009) Effects of used foundry sand on the mechanical properties of concrete. Constr Build Mater 23:976-980

18. Naik TR, Patel VM, Parikh DM, Tharaniyil MP (1994) Utilization of used foundry sand in concrete. J Mater Civ Eng 6(2):254-263
19. Guney Y, Sari YD, Yalcin M, Tuncan A, Donmez S (2010) Reusage of waste foundry sand in high strength concrete. Waste Manag 30:1705-1713

20. Prabhu GG, Hyun JH, Kim YY (2014) Effects of foundry sand as a fine aggregate in concrete production. Constr Build Mater 70:514-521

21. Sahmaran M, Lachemi M, Erdem TK, Yücel HE (2011) Use of spent foundry sand and fly ash for the development of green selfconsolidating concrete. Mater Struct 44:1193-1204

22. Naik TR, Kraus RN, Chun YM, Ramme WB, Singh SS (2003) Properties of field manufactured cast-concrete products utilizing recycled materials. J Mater Civ Eng 15(4):400-407

23. Siddique R, Agarwal Y, Aggarwal P, Kadri EH, Bennacer R (2011) Strength, durability, and micro- structural properties of concrete made with used-foundry sand (UFS). Constr Build Mater 25:1916-1925

24. Manoharan T, Laksmanan D, Mylsamy K, Sivakumar P, Sircar A (2018) Engineering properties of concrete with partial utilization of used foundry sand. Waste Manag 71:454-460

25. Pittenger DM (2017) State-of-the-practice literature scan for foundry sand, Quick Search. Department of Transportation, Oklahoma

26. Ambruster DR, Iyer SR, Pasion MC (1992) Processes and compositions to enhance the tensile strength of reclaimed sand bonded with alkaline resins. US pattern no 5089540

27. Tinker Omega Manufacturing LLC (2018) USR secondary attrition. http://tinkeromega.com/category/usr-secondary-attrition. Accessed 21 Oct 2018

28. British Standards Institution (1992) BS 882:1992: Specification for aggregates from natural sources for concrete. BSI, London

29. British Standards Institution (1995) BS 812-2:1995: Testing aggregates Part 2. Methods of determination of density. BSI, London

30. British Standards Institution (1997) BS 5238-1:1997: ConcretePart 1: guide to specifying concrete. BSI, London

31. British Standards Institution (2009) BS EN 12350-2:2009: Testing fresh concrete. Part 2: Slump test. BSI, London

32. British Standards Institution (2009) BS EN 12350-7:2009: Testing fresh concrete. Part 7: air content-pressure methods. BSI, London

33. Neville AM (1995) Properties of concrete, 4th edn. Longman, Harlow

34. British Standards Institution (2009) BS EN 12390-3:2009: Testing hardened concrete-part 3: compressive strength of test specimens. BSI, London

35. British Standards Institution (2009) BS EN 12390-6:2009: Testing hardened concrete-part 6: tensile splitting strength of test specimens. BSI, London

36. British Standards Institution (1983) BS 1881-121:1983: Testing concrete-part 121: method for determination of static modulus of elasticity in compression. BSI, London

37. British Standards Institution (2009) BS EN 12390-5:2009: Testing hardened concrete-part 5: flexural strength of test specimens. BSI, London

38. British Standards Institution (2011) BS EN 1881-122:2011: Testing concrete part 122: method for determination of water absorption. BSI, London

39. American Society of Testing and Materials (2003) Standard test method for potential alkali reactivity of aggregates (Mortar-Bar Method). In: ASTM C1260-01, Annual Book of ASTM Standards, vol 04.02.2003. ASTM, West Conshohocken

40. British Standard Institution (2006) BS EN 14630: 2006: Products and systems for the protection and repair of concrete structuretest methods-determination of carbonation depth in hardened concrete by the phenolphthalein method. BSI, London 
41. McNally C, Sheils E (2012) Probability-based assessment of the durability characteristics of concretes manufactured using CEM II and GGBS binders. Constr Build Mater 30(5):22-29
Publisher's Note Springer Nature remains neutral with regard to jurisdictional claims in published maps and institutional affiliations. 